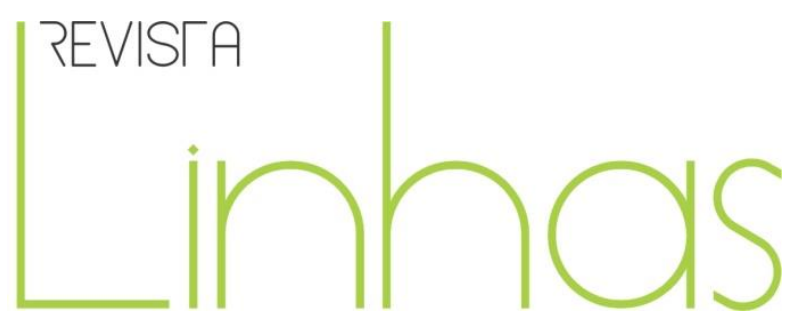

\title{
Ensino de filosofia em perspectiva: contribuições de Nietzsche, Deleuze, Guattari e das diretrizes curriculares de filosofia do estado do Paraná
}

\section{Resumo}

Este artigo tem como objetivo apresentar algumas reflexões sobre a análise dos resultados de pesquisa desenvolvida durante o mestrado no Programa de Pós-Graduação em Educação na Universidade Estadual de Ponta Grossa relacionada ao ensino de Filosofia como experiência filosófica, pois acreditamos e defendemos a ideia de um ensino de Filosofia que não seja meramente enciclopédico. Assim, partindo do pressuposto de que Filosofia é criação de conceitos, buscamos investigar as contribuições de Nietzsche, de Deleuze e Guattari para o seu ensino, além das orientações principais contidas nas Diretrizes Curriculares do Estado do Paraná. Por meio da Análise de Conteúdo de Bardin (2011), analisamos as respostas de 116 professores de Filosofia do Paraná a um questionário preparado no Google Docs. Os resultados da pesquisa indicam que os professores da disciplina, de forma predominante, entendem a importância de compreender o ensino de Filosofia como experiência filosófica, permitindo ao estudante do Ensino Médio criar conceitos.
Fábio Antonio Gabriel

Universidade Estadual de Ponta

Grossa - UEPG - PR/Brasil

fabioantoniogabriel@gmail.com

Ana Lúcia Pereira Baccon

Universidade Estadual de Ponta

Grossa - UEPG - PR/Brasil

ana.baccon@hotmail.com

José Carlos da Silva

Universidade Estadual do Norte do Paraná - UENP - PR/Brasil

jcarlos@uenp.edu.br

Palavras-chave: Filosofia; Estudo e Ensino; Paraná.

\footnotetext{
Para citar este artigo:

GABRIEL, Fábio Antonio; BACCON, Ana Lúcia Pereira; SILVA, José Carlos da. Ensino de filosofia em perspectiva: contribuições de Nietzsche, Deleuze, Guattari e das diretrizes curriculares de filosofia do estado do Paraná. Revista Linhas. Florianópolis, v. 17, n. 35, p. 216-240, set./dez. 2016.
} 


\title{
Philosophy teaching in perspective: contributions of Nietzsche, Deleuze, Guattari and the philosophy curriculum guidelines of Paraná state
}

\begin{abstract}
This paper aims to present some reflections on the analysis of the results of a research developed during the master's degree at the Graduate Program in Education at the State University of Ponta Grossa related to Philosophy teaching as a philosophical experience, as we believe and defend the idea of a Philosophy teaching that is not merely encyclopedic. Thus, assuming that Philosophy is creation of concepts, we seek to investigate Nietzsche and Deleuze's and Guattari contributions for teaching Philosophy, besides the main guidelines contained in the Curriculum Guidelines of the state of Parana. Through Bardin's (2011) content analysis, we analyzed the responses of 116 philosophy teachers from Parana to a questionnaire prepared in Google Docs. The research results indicate that the philosophy teachers predominantly understand the importance of comprehending Philosophy teaching as a philosophical experience allowing the high school students to create concepts.
\end{abstract}

Keywords: Philosophy; Study and Teaching; Paraná. 


\section{Introdução}

É imprescindível destacarmos que a Filosofia retornou recentemente ao currículo do Ensino Médio brasileiro. Na história da Educação no Brasil, assistimos a um movimento pendular de ausência e presença. Quando nos remetemos aos jesuítas, percebemos que a Filosofia tinha também uma finalidade catequética (CARTOLANO, 1985, p. 20). Não podemos deixar de considerar a legítima contribuição dos jesuítas ao ensino de Filosofia e à educação no Brasil, todavia, preocupa-nos que a disciplina tenha sido inserida, desde os primórdios no Brasil, tendo como referência uma dimensão enciclopédica do conhecimento filosófico.

Para discutirmos o papel da Educação na sociedade contemporânea, precisamos levar em conta o processo de formação de professores, tanto inicial e continuada em serviço, bem como o contexto escolar e o contexto das instituições formadoras, pois ambos são primordiais na forma de pensar, de agir e na formação do profissional da educação.

Levando-se em conta esse contexto, o presente artigo tem como objetivo discutir e apontar, por meio de reflexões analíticas, as diferentes formas de perceber a formação docente, tendo como perspectiva o ensino de Filosofia, buscando identificar qual a percepção que os professores apresentam sobre o processo de formação docente a partir do ensino de Filosofia enquanto experiência filosófica.

Por enciclopedismo, entendemos uma forma de se compreender o ensino de Filosofia tendo como objetivo apenas a memorização dos sistemas filosóficos historicamente divididos. Em oposição ao conhecimento enciclopédico, defendemos um ensino enquanto criação conceitual que propicie ao estudante uma experiência filosófica. Entendemos a experiência filosófica como a aula que possibilita ao estudante o exercício filosófico, indo além do enciclopedismo, que não relaciona os conteúdos filosóficos com a existência do estudante.

A partir de nossas investigações, como pesquisadores no Programa de PósGraduação em Educação na Universidade Estadual de Ponta Grossa (PR), no ano de 2014, estudamos as contribuições das teorias de Deleuze e Guatarri e Nietzsche para o ensino de Filosofia. Além disso, investigamos as orientações metodológicas das Diretrizes 
Curriculares de Filosofia - DCE (PARANÁ, 2008) para o ensino da matéria no estado. Nesse artigo, procuraremos apresentar uma síntese das inferências de nossas investigações. Limitaremo-nos a apresentar a reflexão sobre a análise de uma das etapas de nossa pesquisa de campo, a saber: uma pesquisa através do Google Docs, com 116 professores de Filosofia de diversos Núcleos Regionais de Ensino no Paraná.

Aspis e Gallo (2009, p. 49) apresentam que Nietzsche realizou uma forte crítica ao ensino enciclopédico e ao ensino acrítico da História da Filosofia na Alemanha de sua época. Para melhor expressar o alcance de nossas pesquisas, dividimos este artigo em quatro partes: 1) A experiência filosófica e a história da Filosofia; 2) As contribuições de Nietzsche, de Deleuze e Guattari para o ensino de Filosofia; 3) Apresentação das orientações principais das Diretrizes Curriculares de Filosofia do Estado do Paraná; e, 4) Apresentação e análise de dados; além desta introdução e das considerações finais.

\section{A experiência filosófica e a História da Filosofia}

Partimos do pressuposto de que o modo de se entender o ensino de Filosofia não é apenas um aspecto pedagógico, mas é um problema filosófico (RAMOS, 2007, p. 197). Quando consideramos a História da Filosofia, é importante ressaltar que os filósofos partiram da tradição filosófica para escrever suas teorias (CERLETTI, 2009, p. 33). Cerletti (2009, p. 81) apresenta algumas questões preliminares para pensarmos uma didática para o ensino de Filosofia. Um primeiro aspecto é que a aula deve ser o momento propício para o questionamento e não o momento de apenas o professor expor suas explicações filosóficas. Um segundo aspecto é de que o ato de filosofar é subjetivo, ou seja, não há como o professor ocupar o lugar do aluno no movimento pelo conhecimento filosófico e também o estudante irá refletir a partir de suas próprias experiências históricas.

Cerletti (2009, p. 11) problematiza a dificuldade que temos em teorizar o que seria ensinar Filosofia porque temos diversas possibilidades e perspectivas de definir o que ela é. E um questionamento a ser levantado é se é possível transmitir Filosofia. Assim, em última instância, o ensinar Filosofia relaciona-se com o fazer Filosofia, e o filosofar, se sustenta a partir da contribuição da pergunta filosófica. Em outras palavras, entendemos que o seu ensino se realiza de forma muito limitada quando transmite informações da 
História da Filosofia sem uma problematização filosófica que propicie aos estudantes pensarem em seus próprios conceitos e valores.

Quanto ao papel da História da Filosofia, podemos analisar em dois grandes filósofos posições diversas. Por um lado, Kant, que é um filósofo em que prevalece um entendimento de que o filosofar seria mais importante do que o conteúdo histórico da Filosofia. Segundo Obiols (2002), para Kant não se pode, no sentido mais rigoroso do termo, aprender Filosofia porque "não há um saber filosófico aceito" (OBIOLS, 2002, p. 75) e, sim, existem tentativas de um saber filosófico em doutrinas que não são verdades absolutas. Ainda segundo Obiols (2002, p. 76), para Kant só se aprende a filosofar exercitando o talento filosófico sobre sistemas filosóficos já existentes. Em outras palavras, Kant não rejeita a tradição filosófica no exercício do filosofar.

Por outro lado, Hegel, numa perspectiva diferente, compreende que por meio do contato com conteúdos filosóficos, o estudante de Filosofia passa a realizar o exercício do pensamento (RAMOS, 2007, p. 209). Obiols (2002) compreende que, embora sejam perspectivas diferentes, as posições de Kant e Hegel seriam complementares:

\begin{abstract}
Se colocamos Kant um passo à direita e aceitamos que no aprender a filosofar está incluída implicitamente a aprendizagem da filosofia e, se colocamos Hegel um passo à esquerda e admitimos que a filosofia que se deve aprender significa necessariamente aprender a filosofar, superamos uma falsa contradição e podemos afirmar que a aprendizagem filosófica é como uma moeda que tem em uma face a filosofia e na outra o filosofar. Talvez a ênfase em uma ou outra face possa depender da circunstância histórica que nos toque viver. Se, em um certo momento, reagimos contra o academicismo que em nome da filosofia, da rigorosidade do conteúdo e dos textos 'sagrados' inibe a expressão do pensamento próprio, provavelmente possamos nos aferrar e defender, com justiça nas circunstâncias assinaladas, a proposta de aprender a filosofar. (OBIOLS, 2002, p. 81)
\end{abstract}

Do ponto de vista da prática de sala de aula, ambas as posições, de Kant e de Hegel, são capazes de dialogar entre si. É recomendável que o professor encontre um ponto de equilíbrio no que se refere à utilização da História da Filosofia. Por um lado, um extremo é transformar a aula em uma conversa de bar com muito diálogo, mas sem fazer referência a nenhum conteúdo filosófico. Por outro lado, outro extremo é transformar a 
aula de Filosofia numa mera exposição cronológica, enciclopédica da sua história. A experiência filosófica, conforme entendemos, pode ocorrer na medida em que o professor consiga “dosar" a História da Filosofia ao mesmo tempo em que possibilite aos estudantes a manifestação de suas respectivas subjetividades.

Benetti (2006, p. 35) apresenta que o momento da aula de Filosofia é um instante em que é possibilitado ao estudante pensar por si próprio. E, segundo a autora, para pensar por si próprio “é necessário ir além do ensino de habilidades, de pensamento, da história da filosofia e ou de temas" (BENETTI, 2006, p. 35). Nesse sentido, o ato de filosofar tem por característica desacomodar e gerar conflito (no sentido de levar o estudante a um questionamento sobre suas próprias convicções). Benetti (2006, p. 35) alerta que muitas vezes se pressupõe, no estudante, a existência natural de um desejo de pensar, de ser crítico. Pelo contrário, segundo a autora, os sujeitos resistem à homogeneização e seus desejos nem sempre são para exercitar o pensamento filosófico. Ela ainda ressalta que é importante que nós não pensemos em formatar os estudantes, doutrinando-os, mas sim que possibilitemos a eles uma experiência filosófica partindo de sua própria singularidade inédita. Nas palavras da autora:

O processo de ensino, no entanto, se beneficiaria muito se pudesse trabalhar com a perspectiva de que o sujeito não é, não está sempre como que naturalmente predisposto ao pensamento e à reflexão filosófica. É necessária uma implicação, um engate com algo que a filosofia pode oferecer para desencadear o pensamento, e esse engate não passa somente pela ordem da vontade. Implicar-se significa poder fazer algo com aquilo que nos inquieta, com o que mexe com nossas convicções, e construir um lugar, que é singular, para essas inquietações. O importante é que possamos escutar o aluno não para formatá-lo conforme um ideal fixo, mas para criar com ele caminhos diversos que proporcionem o contato com uma forma de pensar que considere a existência da implicação do desejo e da diferença na sua constituição. (BENETTI, 2006, p. 37)

Aspis e Gallo (2009, p. 55) retomam Deleuze com o objetivo de encontrar na História da Filosofia a arte do retrato, no sentido de que por meio dela se possa ter contato com o que foi pensado pela humanidade. Nesse movimento de retomar conceitos criados por pensadores do passado, o estudante é convidado também a pensar novos conceitos. Nessa perspectiva deleuziana, a Filosofia não é um sistema linear e 
evolutivo mas, sim, uma coexistência de problemas filosóficos que constantemente se repetem na História da Filosofia, surgindo novas respostas e conceitos partindo de problemas similares.

Acreditamos que é nisso que se encontra o exercício da Filosofia enquanto experiência filosófica: que o estudante, ao revisitar o que foi elaborado no passado sobre um determinado tema/problema também pense sobre seus próprios conceitos.

Passemos agora a analisar de modo mais específico as contribuições teóricas de Nietzsche, Deleuze e Guattari, e de que maneira suas considerações podem nos auxiliar no que diz respeito a pensar um ensino de Filosofia enquanto experiência filosófica.

\section{As contribuições de Nietzsche, Deleuze e Guattari para o ensino de Filosofia}

Iniciamos relatando as contribuições de Nietzsche para nossa. Primeiramente, exporemos como Nietzsche entende a verdade e, num segundo momento, dissertaremos sobre o seu entendimento acerca do valor dos valores.

É no ensaio "Sobre verdade e mentira num sentido extramoral" que encontramos uma formulação de Nietzsche para o conceito de verdade. O filósofo alemão se pergunta sobre a origem do impulso à verdade presente no ser humano. Nietzsche (1978) inicia o ensaio afirmando que havia um astro em que animais inteligentes inventaram o conhecimento. "Foi o minuto mais soberbo e mais mentiroso da história universal, mas foi também um só minuto" (NIETZSCHE, 1978, p. 45).

Nietzsche (1978) também ridiculariza a maneira como o conhecimento intelectual foi valorizado pelo ser humano. O ser humano se considera o ser mais importante de todo o universo por possuir um intelecto. Nietzsche (1978) ainda afirma que supomos conhecer algo das coisas quando, na realidade, não possuímos mais do que metáforas das coisas. $O$ conceito de verdade em Nietzsche é de que ela é uma metáfora:

O que é a verdade, portanto? Um batalhão móvel de metáforas, metonímias, antropomorfismos, enfim, uma soma de relações humanas que foram enfatizadas poética e retoricamente, transpostas, enfeitadas, e que, após longo uso, parecem a um povo sólidas, canônicas e 
obrigatórias: as verdades são ilusões, das quais se esqueceu que o são, metáforas que se tornaram gastas e sem força sensível, moedas que perderam sua efígie e agora só entram em consideração como metal, não mais como moedas. (NIETZSCHE, 1978, p. 48)

Se pensarmos no ensino de Filosofia tendo como referência esse conceito de verdade, então deixaremos de lado qualquer resquício de doutrinação no seu ensino e passaremos a entender o pensamento filosófico não como algo estático, mas como algo fluído. O próprio paradigma do ser humano considerar-se um ser superior sobre os demais animais passa a ser questionado.

Passemos agora a realizar considerações sobre os valores em Nietzsche. Desde “Humano, demasiado humano", o filósofo alemão passa a intuir que os valores não caíram prontos do céu e sim que são frutos de uma criação histórica. Nietzsche recebeu influência de moralistas franceses como Montaigne e La Rochefoucauld. Nessa obra, o filósofo entra em guerra contra os ideais metafísicos e contra toda espécie de idealismos. Nietzsche (1978) se propõe a uma análise química das representações morais quanto aos sentimentos religiosos e estéticos.

Mas é na obra "Para a Genealogia da Moral”, que o filósofo diagnostica uma análise do "valor dos valores", ou seja, centrada não no significado de quais atitudes são boas, mas na consideração de investigar o que é bom e qual é a própria genealogia do conceito de "bom".

Todo o respeito, pois, pelos bons espíritos que possam reinar nesses historiadores da moral! Mas o que é certo, infelizmente, é que o próprio espírito histórico lhes falta, que eles foram desamparados precisamente por todos os bons espíritos da história! Todos eles pensam, como já é velho uso de filósofos, de modo essencialmente a-histórico: disso não há dúvida nenhuma. A incompetência de sua genealogia da moral vem à luz logo no início, quando se trata de averiguar a proveniência do conceito e juízo "bom". "Temos na origem" - assim decretam eles - ações não egoístas, louvadas, e denominadas boas por parte daqueles a quem foram demonstradas, portanto, a quem foram úteis; mais tarde, temos essa origem do louvor esquecida, e ações não egoístas, simplesmente porque habitualmente eram louvadas como boas, sentidas também como boas - como se fossem em si algo de bom. (NIETZSCHE, 1978, p. 299) 
Para Nietzsche (1978), os valores possuem, portanto, uma história com relação à sua emergência, não foram fixados em uma origem. Pensando no ensino de Filosofia, podemos conceber a aula de Filosofia como o momento que possibilita ao estudante do Ensino Médio pensar sobre seus valores, interrogando-se de que maneira esses valores foram constituídos. Na perspectiva de Nietzsche, somos convidados a entender que cada estudante, durante essa aula, tem a possibilidade de rever seus próprios valores e lhes dar novas configurações.

Nesse sentido de crítica a um mundo metafísico, também converge a Filosofia de Deleuze - filósofo da multiplicidade. Diferente do posicionamento de Marx, que afirmou que os filósofos limitaram-se a refletir sobre o mundo, Deleuze entende que através da criação conceitual, os filósofos realizam uma constante recriação do mundo (GALLO, 2008, p. 35). Pensando na aula de Filosofia enquanto criação de conceitos, é relevante o entendimento de Gallo (2013, p. 57) de que a aula deve ser uma oficina de conceitos:

\begin{abstract}
A aula de Filosofia precisa ser vista como uma "oficina de conceitos" e nunca uma sala de museu, na qual se contemplem conceitos criados há muito tempo e que são vistos como meras curiosidades. Deve-se, assim, atuar como um meio de trabalho em que os conceitos se ofereçam como ferramentas manipuláveis, como um laboratório em que se permita e ofereça condições e meios para experiências e experimentações, de acordo com os conceitos de que esse estudante se apropria. (GALLO, 2013, p. 57)
\end{abstract}

A maneira como Deleuze e Guattari entendem o modo de fazer Filosofia difere do entendimento tradicional que busca uma fundamentação para as realidades desse mundo num mundo transcendental. Criar conceitos, para eles, não é criar verdades fixas e imutáveis. "Os conceitos filosóficos para Deleuze e Guattari não são ideias que seguem regras sistemáticas de organização" (CRUZ; MOSTAFA, 2009, p. 15).

Ao contrário de um fundamento metafísico, Deleuze e Guattari (2010) defendem que para que ocorra o processo de criação conceitual faz-se necessária a criação de um plano de imanência. "É um plano de consistência ou, mais exatamente, o plano de imanência dos conceitos, o planômetro. Os conceitos e o plano são estritamente 
correlativos, mas nem por isso devem ser confundidos" (DELEUZE; GUATTARI, 2010, p. 45).

Deleuze e Guattari (2010) entendem que o plano de imanência não é nem o conceito, nem o conceito dos conceitos. Nesse sentido, a Filosofia é considerada pelos autores como construtivismo que possui dois aspectos complementares: criar conceitos e traçar o plano de imanência. Ainda sobre a relação entre conceitos e o plano, assim afirmam os autores: "Os conceitos são agenciamentos concretos como configurações de uma máquina, mas o plano é a máquina abstrata cujos agenciamentos são as peças" (DELEUZE; GUATTARI, 2010, p. 46). O plano de imanência é pré-filosófico, implicando em uma espécie de "experimentação tateante" e seu "traçado recorre a meios pouco confessáveis, pouco racionais e razoáveis" (DELEUZE; GUATTARI, 2010, p. 52). O plano de imanência age realizando um corte no caos e age como um crivo.

Cruz e Mostafa (2009, p. 24) destacam que, para esses filósofos, os conceitos têm uma história. O exemplo é o conceito de ideia em Platão, que por sua vez remete aos présocráticos, cuja discussão era sobre o elemento primordial. Heráclito defendia a fluidez, que tudo está em constante mudança. Parmênides entendia que o ser sempre permanece. Platão, por sua vez, realizou uma síntese desses conceitos criando o conceito de ideia. Para Deleuze e Guattari, todo conceito remete a um problema e tem componentes que são aproximados por vizinhança (CRUZ; MOSTAFA, 2009, p. 40).

A tradição filosófica pensou a Filosofia numa perspectiva tradicional, tendo relação de significado com três verbos que seriam: contemplar, refletir e comunicar (FAVRETO, 2013, p. 14). Esses três verbos sempre remeteram a outro mundo, a uma unidade transcendente. A contemplação visa uma coisa pretendida, mas não cria (FAVRETO, 2013, p. 16). Já a reflexão não é campo apenas do filósofo; qualquer pessoa pode refletir sobre o que desejar sem necessitar da Filosofia. E a comunicação, "por fim, busca um consenso, um acordo entre as partes de um diálogo" (FAVRETO, 2013, p. 16). "Vemos ao menos o que a Filosofia não é: ela não é contemplação, nem reflexão, nem comunicação" (DELEUZE; GUATTARI, 2010, p. 12). Ou, em outras palavras: "A filosofia não contempla, não reflete, não comunica, se bem que ela tenha de criar conceitos para estas ações ou paixões" (DELEUZE; GUATTARI, 2010, p. 13). 
Nesse sentido, quando pensamos em ensino de Filosofia no Ensino Médio, dentro de um entendimento da Filosofia, enquanto criadora de conceitos, percebemos o desafio didático para que o professor consiga propiciar ao estudante uma experiência filosófica com conceito. Deleuze e Guattari compreendem a História da Filosofia como uma reconstrução conceitual. Didaticamente pensando, o professor de Filosofia poderia realizar o exercício de apresentar aos alunos alguns conceitos e verificar como eles se modificaram ao longo da História da Filosofia.

Deleuze e Guattari (2010, p. 75) ainda apresentam que os filósofos, além de instalarem um plano de imanência, também criaram personagens conceituais e são esses personagens que "operam os movimentos que descrevem o plano de imanência do autor e intervêm na própria criação de conceitos" (DELEUZE;GUATTARI, 2010, p. 78). Os autores afirmam ainda que a História da Filosofia é desinteressante por inteira, caso não se proponha a "despertar um conceito adormecido, a relançá-lo numa nova cena, mesmo a preço de voltá-lo contra ele mesmo" (DELEUZE; GUATARRI, 2010, p. 101).

Na próxima seção, discorreremos sobre as principais orientações das Diretrizes Curriculares do Paraná e seu entendimento da Filosofia enquanto criadora de conceitos.

\section{Apresentação das orientações principais das Diretrizes Curriculares de Filosofia do Estado do Paraná}

Mendes (2008, p. 92) relata os diversos encontros de professores de Filosofia do Paraná que permitiram que, paulatinamente, fosse elaborado o texto atual das Diretrizes Curriculares de Filosofia do Paraná - DCE (PARANÁ, 2008). O primeiro encontro se deu nos dias 2 e 3 de outubro de 2003. "O evento não foi centrado em falas magistrais onde os presentes deveriam aprender aquilo que alguém Ihes falasse". Existiram diversos outros encontros até que fosse elaborada a versão atual das DCE (PARANÁ, 2008). Mendes (2008, p. 99) relata que muitos esperavam uma opção declarada do texto das DCE pelo materialismo histórico, e ficaram surpresos quando as DCE assumiram o entendimento da Filosofia enquanto criação de conceitos.

As DCE iniciam com uma espécie de preâmbulo que é comum ao texto das demais disciplinas. O preâmbulo é denominado "A educação básica e a opção pelo currículo 
disciplinar”. A parte I do preâmbulo "Os sujeitos da educação básica” preocupa-se em questionar as origens e a caracterização dos estudantes da escola pública no Paraná. O texto enfatiza que as referências metodológicas a serem buscadas devem ser aquelas que proporcionem a emancipação dos estudantes. Ao longo do preâmbulo é mencionada a existência de um currículo documento que nem sempre é o currículo do cotidiano escolar. O documento faz menção a diversas formas de se compreender o currículo, mas que as DCE fazem uma opção pelo currículo como configurador da prática, vinculado às teorias críticas.

O preâmbulo das DCE destaca ainda que o currículo da educação básica deve oferecer ao estudante, "a formação necessária para o enfrentamento com vistas à transformação da realidade social, econômica e política de seu tempo" (PARANÁ, 2008, p. 20).

De uma forma geral, as orientações contidas nas DCE (PARANÁ, 2008, p. 38), no texto específico da disciplina Filosofia, estão organizadas e divididas em cinco capítulos, a saber: Dimensões históricas da Filosofia e seu ensino; Fundamentos teóricometodológicos; Conteúdos estruturantes; Encaminhamentos metodológicos e Avaliação.

No primeiro capítulo é apresentada uma preocupação com as metodologias de ensino de Filosofia, com o objetivo de que "os métodos de ensino não deturpem o conteúdo" (PARANÁ, 2008, p. 38). Diante das possíveis divisões dos conteúdos de Filosofia (divisão cronológica, linear, divisão geográfica e divisão por conteúdos), as DCE concebem o ensino de Filosofia através de conteúdos estruturantes.

Esse modo de conceber, segundo o texto das DCE, absorve as divisões cronológicas e geográficas. O texto ainda destaca as origens históricas do ensino de Filosofia no Brasil, fazendo um retrospecto desde o surgimento da Filosofia no país, com os jesuítas, chegando até a Lei $n^{\circ}$ 9394/96, que no seu artigo 36 determinava que, ao final do Ensino Médio, o aluno deveria dominar os conhecimentos necessários de Filosofia e Sociologia para o exercício da cidadania.

No Estado do Paraná, em julho de 2006, foi aprovada a Lei $n^{\circ} 15.228$, que tornava as disciplinas de Filosofia e Sociologia obrigatórias na matriz curricular do Ensino Médio. O texto desse capítulo ainda faz um questionamento sobre qual Filosofia ensinar diante 
de diversas compreensões sobre o que é Filosofia. Um dos aspectos apontados é a dimensão política que a Filosofia deve possuir. "A Filosofia é filha da ágora e sua origem a vincula à política. Uma filosofia sem compromissos com a humanidade e distante da política, seria por si só uma contradição insuperável” (PARANÁ, 2008, p. 48). E são apresentadas as potencialidades que a Filosofia deve desenvolver no estudante, a saber:

Capacidade de indagação e crítica; qualidades de sistematização, de fundamentação, rigor conceitual; combate a qualquer forma de dogmatismos e autoritarismo; disposição para levantar novas questões, para repensar, imaginar e construir conceitos, além da sua defesa radical de emancipação humana, do pensamento e da ação, livres de qualquer forma de dominação. (PARANÁ, 2008, p. 48)

No segundo capítulo são apresentados os fundamentos teóricos e metodológicos, apresentando as três idades do conceito: a primeira idade do conceito, a enciclopédica; a segunda idade do conceito, a pedagógica; e, a terceira idade do conceito, a formação profissional comercial. Tais idades do conceito são fundamentadas partindo dos pressupostos teóricos de Deleuze e Guattari (2010). A opção pelo entendimento da filosofia enquanto criação conceitual pelas DCE (PARANÁ, 2008, p. 50) é explicitada nos dizeres do texto: "O ensino de Filosofia é um espaço para análise e criação de conceitos, que une a Filosofia e o filosofar como atividades indissociáveis que dão vida ao ensino dessa disciplina juntamente com o exercício da leitura e da escrita”.

O texto ainda afirma que é necessário superar a idade do conceito enciclopédico e é necessário opor-se à idade da formação profissional do conceito; desse modo, realiza uma opção pela idade pedagógica do conceito. O entendimento do texto das DCE é esclarecedor quanto ao fato de que o ensino de Filosofia deve propiciar uma experiência filosófica ao estudante que permita uma ultrapassagem do ensino meramente enciclopédico. "O ensino de filosofia como criação de conceitos deve abrir espaço para que o estudante possa planejar um sobrevoo sobre todo o vivido, a fim de que consiga à sua maneira, também, cortar, recortar a realidade e criar conceitos" (PARANÁ, 2008, p. 52). E ainda que: "O trabalho do professor poderá assegurar ao estudante a experiência daquilo que é específico da atividade filosófica, ou seja, a criação de conceitos" (PARANÁ, 2008, p. 53). 
No terceiro capítulo são apresentados os conteúdos estruturantes, a saber: Mito e Filosofia; Teoria do Conhecimento; Ética, Filosofia Política, Filosofia da Ciência e Estética. O texto mostra que essa abordagem de conteúdos estruturantes não exclui de forma alguma a História da Filosofia, na medida em que os conteúdos estruturantes fazem parte dela. É enfatizado que as DCE buscam superar a concepção enciclopédica de Filosofia.

Sobre o conteúdo estruturante Mito e Filosofia, destaca-se que é por meio dele que é permitido estudar as relações entre pensamento mítico e pensamento racional e as condições para surgimento da Filosofia no século VI a.C. Em relação ao conteúdo estruturante Teoria do Conhecimento, é evidenciado que esse conteúdo procura estudar os critérios de verdade, investigar a possibilidade do conhecimento, o âmbito do conhecimento e interrogar-se sobre qual é a fonte do conhecimento. O texto define Ética como "o estudo dos fundamentos da ação humana" (PARANÁ, 2008, p. 57) e ainda apresenta que o conteúdo Ética possibilita uma análise crítica dos valores, a importância de se considerar os desafios da ética na vida contemporânea como, por exemplo, o crescimento dos fundamentalismos religiosos e do "pragmatismo político que busca reordenar os espaços privados e públicos" (PARANÁ, 2008, p. 58).

Outro conteúdo estruturante apresentado é Filosofia Política, considerado relevante na medida em que possibilita compreender "os mecanismos que estruturam e legitimam os diversos sistemas políticos” (PARANÁ, 2008, p. 58). O penúltimo conteúdo estruturante é Filosofia da Ciência, que consiste no "estudo crítico dos princípios, das hipóteses e dos resultados das diversas ciências. Sua importância consiste em refletir criticamente sobre o conhecimento científico" (PARANÁ, 2008, p. 59). O texto ressalta que é importante estudar a Filosofia da Ciência no Ensino Médio na perspectiva "da produção e do produto do conhecimento científico, problematizar o método e possibilitar o contato com o modo como os cientistas trabalham e pensam" (PARANÁ, 2008, p. 59).

O último conteúdo estruturante a ser apresentado é Estética, cujo objetivo é “compreender a sensibilidade, a representação criativa, a apreensão intuitiva do mundo concreto e a forma como elas determinam as relações do homem com o mundo" (PARANÁ, 2008, p. 59). Desse modo, através desse conteúdo estruturante, cabe ao estudante perceber como a beleza foi entendida de diversas formas ao longo da história 
da humanidade e, nesse sentido, também realizar uma crítica ao mercado do gosto que através dos meios de comunicação de massa agem no sentido de formar os gostos de forma massiva.

No quarto capítulo, intitulado “Encaminhamentos metodológicos”, encontramos a orientação de que a aula deve ser dividida em quatro momentos ao se trabalhar com os conteúdos estruturantes, a saber: a mobilização para o conhecimento; a problematização; a investigação e a criação de conceitos. A mobilização para o conhecimento é o momento em que o professor pode utilizar-se, por exemplo, de um trecho de filme ou da leitura de um texto jornalístico com o objetivo de mobilizar o estudante para o conhecimento. Posteriormente, o professor deve problematizar. "A problematização ocorre quando o professor e estudantes levantam questões, identificam problemas e investigam o conteúdo" (PARANÁ, 2008, p. 60). Da problematização, seguese para a investigação e a criação de conceitos. Na investigação, o professor pode utilizarse de textos filosóficos, observando como os filósofos da tradição pensaram determinados conceitos e responderam a determinadas problematizações. E como etapa final, ao estudante é propiciada a experiência filosófica criando conceitos:

\begin{abstract}
Dessa forma, a partir de problemas atuais estudados da História da Filosofia, do estudo dos textos clássicos e de sua abordagem contemporânea, o estudante do Ensino Médio pode formular conceitos e construir seu discurso filosófico. O texto filosófico que ajudou os pensadores a entender a analisar filosoficamente o problema em questão será trazido para o presente com o objetivo de entender o que ocorre hoje e como podemos, a partir da Filosofia, atuar sobre os problemas de nossa sociedade. (PARANÁ, 2008, p. 60)
\end{abstract}

No quinto capítulo, mostra-se que a disciplina de Filosofia possui uma especificidade que deve ser levada em conta durante o momento do processo de avaliação. Os seus pressupostos da avaliação devem considerar, segundo o texto das DCE (PARANÁ, 2008, p. 62), qual discurso o estudante tinha antes; qual conceito trabalhou; qual discurso tem após e qual conceito trabalhou. Desse modo, trata-se de verificar se o estudante realizou uma experiência filosófica da criação conceitual, ao invés de se ater apenas ao enciclopedismo, que se limita a uma visão apenas de memorização dos 
conteúdos filosóficos. Realizadas essas considerações sobre as orientações das DCE (PARANÁ, 2008), passamos para a apresentação e análise da pesquisa de campo.

\section{Apresentação e análise de dados}

A pesquisa que aqui está sendo tratada é de natureza qualitativa, por existir maior interesse pelo processo do que pelos resultados (BOGDAN; BIKLEN, 1994, p. 48). Trivinos (1987) apresenta que na pesquisa qualitativa o "pesquisador não inicia seu trabalho orientado por hipóteses levantadas a priori, cuidando de todas as alternativas possíveis, que precisam ser verificadas empiricamente" (TRIVINOS, 1987, p. 131). Flick (2009) afirma que a subjetividade do pesquisador é parte integrante dos processos de pesquisas qualitativas.

Na presente pesquisa, a coleta de dados foi efetivada por meio de questionário aplicado a 116 professores dos diversos Núcleos Regionais de Ensino (NRE) do Paraná, realizada através do Google Docs. Os sujeitos da pesquisa foram contatados por meio de e-mail enviado aos técnicos pedagógicos de cada Núcleo Regional de Ensino do Paraná, que por sua vez o repassaram para os professores a eles vinculados em cada Núcleo Regional de Ensino.

Quanto ao questionário, as seis primeiras questões trataram da caracterização dos sujeitos e as demais trataram sobre a importância da história da Filosofia no Ensino de Filosofia; a utilização ou não dos textos filosóficos em sala de aula; a importância dada pelos professores quanto ao texto das DCE (PARANÁ, 2008, p. 80), a divisão em momentos em cada aula de Filosofia; como os professores entendem a avaliação em Filosofia; sobre as contribuições de Nietzsche, Deleuze e Guattari para o Ensino de Filosofia. O quadro abaixo apresenta a caracterização dos sujeitos de pesquisa: 


\begin{tabular}{|c|c|c|c|}
\hline \\
\hline Elementos & Opções de respostas & Respostas & $\%$ \\
\hline \multirow{3}{*}{$\begin{array}{l}\text { Graduação } \\
\text { (Questão 1) }\end{array}$} & $\begin{array}{l}\text { Possui graduação em } \\
\text { Filosofia }\end{array}$ & 100 & 86 \\
\hline & $\begin{array}{l}\text { Possui graduação em } \\
\text { Ciências Humanas }\end{array}$ & 11 & 10 \\
\hline & $\begin{array}{l}\text { Possui graduação em } \\
\text { outras áreas }\end{array}$ & 5 & 5 \\
\hline \multirow{5}{*}{$\begin{array}{l}\text { Há quanto tempo leciona a disciplina de } \\
\text { Filosofia } \\
\text { (Questão 2) }\end{array}$} & Menos de 01 ano & 4 & 3 \\
\hline & Entre 01 e 05 anos & 64 & 55 \\
\hline & Entre 05 e 10 anos & 31 & 27 \\
\hline & Entre 10 e 20 anos & 13 & 11 \\
\hline & Mais de 20 anos & 4 & 3 \\
\hline \multirow{5}{*}{$\begin{array}{l}\text { Faixa etária } \\
\text { (Questão 3) }\end{array}$} & Menos de 25 anos & 15 & 13 \\
\hline & Entre 25 e 35 anos & 49 & 42 \\
\hline & Entre 35 e 45 anos & 33 & 28 \\
\hline & Entre 45 e 55 anos & 17 & 15 \\
\hline & Mais de 55 anos & 2 & 2 \\
\hline \multirow{2}{*}{$\begin{array}{c}\text { Sexo } \\
\text { (Questão 4) }\end{array}$} & Masculino & 58 & 50 \\
\hline & Feminino & 58 & 50 \\
\hline $\begin{array}{c}\text { NRE } \\
\text { (Questão 5) }\end{array}$ & \multicolumn{3}{|c|}{$\begin{array}{l}\text { Houve amostragem de núcleos regionais de todo o } \\
\text { Paraná }\end{array}$} \\
\hline \multirow{2}{*}{$\begin{array}{l}\text { Regime de trabalho } \\
\text { (Questão 6) }\end{array}$} & QPM & 56 & $48 \%$ \\
\hline & PSS & 60 & $52 \%$ \\
\hline
\end{tabular}

Fonte: Os autores (2015).

A análise de conteúdos foi realizada através dos pressupostos teóricos da Análise de Conteúdo de Bardin (2011). A organização da análise se distribui por três momentos: a pré-análise; a exploração do material; o tratamento dos resultados mediante inferência e interpretação. Seguindo também Bardin (2011), foi realizada a divisão das respostas em duas categorias, através dos três momentos apresentados acima.

A primeira categoria foi denominada de "Entendimentos com relação às Diretrizes Curriculares de Filosofia do Paraná" (PARANÁ, 2008) e a segunda foi denominada “Entendimento sobre os referenciais teóricos de Nietzsche, Deleuze e Guattari”. Outras questões realizadas aos professores versaram sobre elementos metodológicos do ensino de Filosofia, todavia, não serão expostos os resultados sobre essas questões nesse momento. 


\subsection{Categoria I - Entendimentos com relação às Diretrizes Curriculares de Filosofia do Paraná}

Dos 116 professores da rede estadual, quando questionados sobre como entendem as Diretrizes Curriculares de Filosofia do Estado do Paraná - DCE, (questão 9) 98 dos entrevistados (85\%) responderam que a percebem como um subsídio importante que contém orientações de relevância didática para o cotidiano do professor. De outra parte, 18 (15\%) responderam que se trata de um subsídio teórico que contém apenas informações teóricas que acabam não contribuindo com a realidade de cada professor. Uma questão que, talvez, não tenha sido verificada foi em que medida cada professor tem efetivo conhecimento das DCE de Filosofia, sendo que entre os 18 que afirmam que é apenas um subsídio teórico, poderíamos questionar, no universo dos 116 professores, quantos teriam conhecimento sobre as Diretrizes Curriculares de Filosofia e de suas principais orientações.

Embora nessa questão seja elevado o percentual daqueles que afirmam que as DCE de Filosofia são relevantes, na próxima questão (de $\left.n^{\circ} 10\right)$, percebemos que aumenta o número daqueles que não seguem a recomendação da divisão da aula em momentos (mobilização para o conhecimento, a problematização, a investigação e a formação de conceitos). O texto das DCE orienta com os seguintes dizeres:

O trabalho com os conteúdos estruturantes da Filosofia e seus conteúdos básicos dar-se-á em quatro momentos: a mobilização para o conhecimento; a problematização; a investigação; a criação de conceitos. [...] Ao final desse processo, o estudante, via de regra, encontrar-se-á apto a elaborar um texto, no qual terá condições de discutir, comparar e socializar ideias e conceitos. Após esse exercício, o estudante poderá perceber o que está e o que não está implícito nas ideias, como elas se tornam conhecimento e, por vezes, discurso ideológico, de modo que ele desenvolva a possibilidade de argumentar filosoficamente, por meio de raciocínios lógicos, num pensar coerente e crítico. (PARANÁ, 2008, p. 45)

Entre os entrevistados, 84 (73\%) responderam que utilizam com frequência essa dinâmica da divisão em momentos da aula de Filosofia, por entenderem que é relevante para a aprendizagem dos estudantes; 6 (5\%) desconsideram esses momentos e já iniciam com os conteúdos que serão trabalhados ao invés de proporem uma mobilização para o 
conhecimento, inicialmente; e, 26 (22\%) acreditam que o professor não tem tempo para preparar aulas com todos esses momentos, tendo em vista a exigência de que o professor busque diversos outros recursos além do livro didático.

Na prática, por essa resposta, podemos inferir que, mesmo que alguns professores considerem as DCE de Filosofia um subsídio importante do ponto de vista teórico, na prática houve um aumento do número de entrevistados que afirmam ou que não têm tempo para preparar, ou que essa (que é uma das orientações das DCE) não é viável na vida prática cotidiana do professor. Todavia, não podemos deixar de realçar que a maioria (73\%) considera importante essa divisão da aula em momentos e afirma que divide sua aula dessa maneira.

Desse modo, através dessa categoria, podemos inferir que, predominantemente, há um reconhecimento da importância das DCE enquanto referenciais teóricos e metodológicos para o ensino de Filosofia no Paraná e, também, há um bom número de professores que consideram relevante a orientação das DCE de dividir em momentos a aula de Filosofia.

É importante considerar a preocupação do texto das DCE (PARANÁ, 2008, p. 46): “A preocupação maior com a delimitação de metodologias para o ensino de Filosofia é garantir que os métodos de ensino não lhe deturpem o conteúdo". Assim, parece relevante que os professores de Filosofia do Paraná utilizem as orientações das DCE para propiciarem aos estudantes aulas em que se exercite o pensamento filosófico. Como destacam as DCE, os professores, ao pensarem um ensino de Filosofia, enquanto criação conceitual, poderão "se surpreender com os resultados obtidos ao final do processo. $O$ planejamento deve impedir que as aulas caiam no vazio e nos prováveis desastres do espontaneísmo" (PARANÁ, 2008, p. 61). 


\subsection{Categoria II - Entendimento sobre os referenciais teóricos Nietzsche, Deleuze e Guattari}

Quanto aos nossos referenciais teóricos, inicialmente, pensando na questão de Nietzsche e o valor dos valores, conforme é proposto na obra "Para a Genealogia da Moral" e, conforme a orientação das próprias Diretrizes quanto à questão dos valores (conteúdo estruturante Ética), percebemos que apenas 4 (5\%) dos entrevistados entendem que a aula de Filosofia deve apresentar com objetividade os grandes pensadores que realizaram suas reflexões éticas e desconsiderar a subjetividade do estudante; 112 (95\%), por outro lado, acreditam que a aula de Filosofia deve ser o momento em que se possibilite ao estudante realizar uma experiência filosófica que propicie, ao mesmo tempo, uma reflexão sobre seus valores e uma autorreflexão sobre a origem deles; e nenhum entrevistado respondeu que a aula de filosofia não deve tratar de temas relacionados com os valores, na medida em que são temas que acabam por causar discussões desnecessárias em sala de aula. O texto das DCE assim orienta em relação ao conteúdo estruturante Ética:

A ética possibilita análise crítica para atribuição de valores. Pode ser ao mesmo tempo especulativa e normativa, crítica de heteronomia e da anomia e propositiva na busca de autonomia. Por isso, a ética possibilita o desenvolvimento de valores, mas pode ser também o espaço de transgressão, quando valores impostos pela sociedade se configuram como instrumentos de repressão, violência e injustiça. A ética enquanto conteúdo escolar tem por foco a reflexão da ação individual ou coletiva na perspectiva da Filosofia. Mais que ensinar valores específicos trata-se de mostrar que o agir fundamentado propicia consequências melhores e mais racionais que o agir sem razão ou justificativas. (PARANÁ, 2008, p. 57)

Quanto à opção realizada pelas DCE de que o ensino de Filosofia no Paraná é entendido como criação de conceitos, que é o entendimento de Deleuze e Guattari sobre o seu ensino, vale ressaltar que 24 (20\%) responderam que não utilizam tal proposta porque a desconhecem; ou seja, desconhecem as próprias DCE de Filosofia. De outro lado, 90 (79\%) acreditam que ela pode ser utilizada porque auxilia os estudantes a pensarem nos seus próprios conceitos e apenas $2(2 \%)$ responderam que não pode ser 
utilizada porque é uma proposta de um filósofo francês e desconsidera a realidade educacional brasileira. Assim, podemos entender que é considerada relevante a contribuição de Deleuze e Guattari (2010) para se pensar um ensino de Filosofia que seja uma autêntica experiência filosófica. Nesse sentido, Deleuze e Guattari (2010, p. 11) confirmam que o filósofo é amigo do conceito:

O filósofo é o amigo do conceito, ele é conceito em potência. Quer dizer que a filosofia não é uma simples arte de formar, inventar ou de fabricar conceitos, pois os conceitos não são necessariamente formas, achados ou produtos. A filosofia, mais rigorosamente, é a disciplina que consiste em criar conceitos. $\mathrm{O}$ amigo seria o amigo de suas próprias criações? Ou então é o ato do conceito que remete à potência do amigo, na unidade do criador e de seu duplo? Criar conceitos sempre novos é o objeto da filosofia. É porque o conceito deve ser criado que ele remete ao filósofo como aquele que o tem em potência, ou que tem sua potência e sua competência. (PARANÁ, 2008, p. 11)

Através dessa categoria, pudemos perceber que de modo preponderante os professores de Filosofia do Paraná compreendem como relevantes as contribuições de Nietzsche, Deleuze e Guattari para o ensino de Filosofia. Trata-se de filósofos contemporâneos que têm em comum o aspecto de valorizarem o imanente, realizando uma crítica à tradição filosófica que valorizou o transcendente. Os três filósofos, sobretudo, contribuem para que pensemos num ensino de Filosofia que não seja meramente enciclopédico e, sim, que seja uma verdadeira experiência filosófica permitindo aos estudantes criar conceitos e/ou avaliar o valor dos valores. 


\section{Considerações finais}

Apresentamos neste artigo reflexões concernentes a uma investigação do pensamento de Nietzsche, de Deleuze e de Guattari e à contribuição que tais filósofos oferecem para a aplicação das Diretrizes Curriculares de Filosofia do Estado do Paraná, em referência ao ensino de Filosofia; destaque-se a perspectiva deleuziana que afirma que a Filosofia consiste na criação de conceitos. Partimos do pressuposto de que o ensino de Filosofia não se resume a mera discussão pedagógica; trata-se, na verdade, de um problema filosófico, uma questão complexa, na medida em que aponta perspectivas sobre o entendimento daquilo que é a Filosofia.

Nossas investigações, longe de propiciarem afirmações definitivas, suscitam reflexões e questionamentos sobre o ensino de filosofia como uma experiência filosófica. O objetivo desta investigação consistiu em verificar em que medida uma aula de Filosofia permite um "ir além" do ensino meramente enciclopédico para se ensinar a pensar, a refletir, a buscar os porquês a respeito dos conceitos em referência. Ressaltemos o entendimento ao termo enciclopedismo como um ensino de filosofia centrado unicamente em uma estéril memorização dos sistemas filosóficos historicamente constituídos, ou seja, sem que uma mínima ideia mais produtiva suscite a curiosidade capaz de induzir o estudante a pensar.

Em Nietzsche (1978), constatamos que a forma como o pensador coloca a metáfora e como entende o valor dos valores ajuda-nos a pensar um ensino de Filosofia que seja uma experiência filosófica e não apenas um ensino enciclopédico de sistemas filosóficos. Quando a verdade não é mais imutável e os fundamentos metafísicos dos valores são duramente criticados, abre-se espaço na aula de Filosofia para o diálogo e para que cada estudante possa questionar os seus próprios valores e os valores vigentes na sociedade. Trabalhar com o aluno uma oportunidade de se pensar o valor dos valores significa possibilitar que a aula se torne um momento de reflexão ética, em que se busca verificar a genealogia dos valores vigentes numa determinada comunidade. Muitos filósofos já haviam refletido acerca dos valores, mas Nietzsche, em particular, destaca o valor dos valores, discutindo a genealogia dos valores. Nossa investigação sobre o referencial teórico de Nietzsche nos permitiu concluir que defendemos a aula de Filosofia como um momento todo especial em que aos estudantes é oferecida a oportunidade não 
apenas de refletir sobre a ética, mas de refletir também sobre as diversas perspectivas de hierarquia dos valores. No que concerne aos resultados de nossa pesquisa, podemos evidenciar que a aula de Filosofia não deve ser entendida apenas como um momento de se memorizarem teorias éticas, mas como uma rara oportunidade em que se convida o estudante a pensar a respeito da genealogia dos valores e das relações de forças que engendram determinados valores.

Em Deleuze e Guattari (2010), percebemos contribuições no sentido de se pensar não mais segundo a concepção de que Filosofia é reflexão, comunicação e contemplação, porque tais entendimentos evocam um mundo transcendente. Deleuze e Guattari (2010) valorizam o imanente; entendem os filósofos em referência à história da Filosofia não em aspecto linear, mas como uma gama de conceitos complexos, criados, recriados e reformulados. As Diretrizes Curriculares de Filosofia do Paraná, com sua opção pelo entendimento da Filosofia enquanto criação de valores, defendem a superação do entendimento do ensino não mais calcado no enciclopedismo, caminhando para um ensino de Filosofia enquanto experiência filosófica. Assim, Deleuze e Guattari (2010), ao ressaltarem o entendimento de que a Filosofia consiste na criação de conceitos, podem oferecer o enriquecimento necessário para as aulas, sobretudo ao lembrar que, para criar conceitos, é necessário instaurar um plano de imanência. O conceito de imanência opõese ao conceito de transcendência; ou seja, a Filosofia de Deleuze parte do imanente, diferente da tradição filosófica, cujo enfoque recai sobre a transcendência. Entendemos, assim, que a aula de Filosofia deve se nortear pela criação de conceitos, que consiste naquele procedimento que permite ao estudante expressar sua maneira inédita de elaborar conceitos e ressignificar sua própria existência ao pensar o "valor” dos valores.

A pesquisa de campo demonstrou que, de modo predominante, os professores de Filosofia do Paraná valorizam as orientações contidas nas DCE, havendo mesmo um reconhecimento das contribuições de Deleuze e de Nietzsche para se pensar o ensino de filosofia. Ressalte-se que $96 \%$ dos professores acreditam que a aula de Filosofia deve ser o momento em que o aluno deva exercitar uma experiência filosófica que propicie a ele a oportunidade de formar conceitos e/ou avaliar o valor dos valores.

Esperamos, em futuros estudos, aprofundar contribuições teóricas de outros pensadores que auxiliem a pensar um ensino de Filosofia que não deseje formatar o 
modo de pensar dos estudantes mas, sim, instiguem a todos eles ao constante, incitemnos ao questionamento diante da verdade, que é metafórica e fluida.

Nossa pesquisa contribui no sentido de se pensar um ensino de Filosofia como um problema filosófico e não mais ser tratado como questão meramente pedagógica. Os resultados da pesquisa de campo permitem inferir que os professores de Filosofia, sujeitos da pesquisa, estão cientes da importância de se pensar um ensino de filosofia que possibilite aos estudantes uma experiência filosófica e não apenas uma repetição de doutrinas filosóficas. Ressaltamos, ainda, que, didaticamente, parece relevante a contribuição de orientação das Diretrizes Curriculares de Filosofia do Estado do Paraná no sentido de a aula se processar em momentos distintos, a saber: a mobilização para o conhecimento; a problematização; a investigação, e a criação de conceitos. Tal divisão permite didaticamente que o professor construa a aula de forma a criar possibilidades para que o estudante possa criar conceitos.

\section{Referências}

ASPIS, Renata Lima; GALLO, Silvio. Ensinar filosofia: um livro para professores. São Paulo: Atta Mídia e Educação, 2009.

BARDIN, Laurence. Análise de conteúdo. São Paulo: Edições 70, 2011.

BOGDAN, Robert; BIKLEN, Sari Knopp. Investigação qualitativa em educação: uma introdução à teoria e aos métodos. Portugal: Porto, 1994.

BENETTI, Cláudia Cisiane. Filosofia e ensino: singularidade e diferença entre Lacan e Deleuze. Ijuí: Unijuí, 2006 (Coleção Filosofia e Ensino).

CARTOLANO, Maria Tereza Penteado. Filosofia no ensino de $2^{\circ}$ grau. São Paulo: Cortez, 1985 .

CERLETTI, Alejandro. O ensino de filosofia como problema filosófico. Belo Horizonte: Autêntica, 2009. 
CRUZ, Denise Viuniski da Nova; MOSTAFA, Solange Puntel. Para ler a filosofia de Gilles Deleuze e Félix Guattari. Campinas: Alínea, 2009.

DELEUZE, Gilles; GUATTARI, Félix. O que é a filosofia? Rio de Janeiro: Editora 34, 2010.

FAVRETO, Kleber Elemar. O filósofo educador e a filosofia criadora:uma análise da “pedagogia do conceito" de Deleuze e Guattari. Polymatheia, v.6, n.9, 2013.

FLICK, Uwe. Métodos de pesquisa: uma introdução à pesquisa qualitativa. Porto Alegre: Artmed, 2009.

GALLO, Sílvio. Deleuze \& educação. Belo Horizonte: Autêntica, 2008.

GALLO, Sílvio. Metodologia do ensino de filosofia: uma didática para o ensino médio. Campinas: Papirus, 2013.

MENDES, Ademir Aparecido P. A construção do lugar da filosofia no currículo do ensino médio: análise a partir da compreensão dos professores de filosofia da escola pública paranaense. 2008. Dissertação (Mestrado em Educação) - Universidade Federal do Paraná, Curitiba, 2008.

NIETZSCHE, Friedrich. Obras incompletas. Tradução de Rubens R. Torres Filho. São Paulo: Abril Cultural, 1978 (Coleção Os Pensadores).

OBIOLS, Guilhermo. Uma introdução ao ensino de filosofia. ljuí: Unijuí, 2002.

PARANÁ, Diretrizes curriculares da educação básica - filosofia. 2008. Disponível em: <http://www.diaadiaeducacao.pr.gov.br/diaadia/diadia/arquivos/File/diretrizes_2009/Filos ofia.pdf>. Acesso em: 15 jun. 2014.

RAMOS, Cesar Augusto. Aprender a filosofar ou aprender a filosofia:Kant ou Hegel? Trans/form/Ação. São Paulo: v.30, n.2, p.197-217, 2007.

TRIVINOS, Augusto Nibaldo Silva Introdução à pesquisa em ciências sociais: pesquisa qualitativa em educação. São Paulo: Atlas, 1987.

Recebido em: 11/05/2015 Aprovado em: 03/11/2015

Universidade do Estado de Santa Catarina - UDESC Programa de Pós-Graduação em Educação - PPGE Revista Linhas Volume 17 - Número 35 - Ano 2016 revistalinhas@gmail.com 